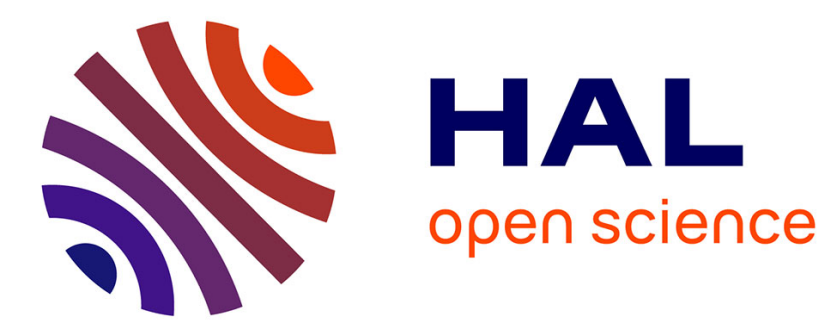

\title{
Study on Finding Effective Measures in Education to Counter Googling Action Based on TRIZ
}

\author{
Yutaka Takafuji
}

\section{To cite this version:}

Yutaka Takafuji. Study on Finding Effective Measures in Education to Counter Googling Action Based on TRIZ. 19th International TRIZ Future Conference (TFC), Oct 2019, Marrakesh, Morocco. pp.497-507, 10.1007/978-3-030-32497-1_39 . hal-02905539

\section{HAL Id: hal-02905539 \\ https://inria.hal.science/hal-02905539}

Submitted on 23 Jul 2020

HAL is a multi-disciplinary open access archive for the deposit and dissemination of scientific research documents, whether they are published or not. The documents may come from teaching and research institutions in France or abroad, or from public or private research centers.
L'archive ouverte pluridisciplinaire HAL, est destinée au dépôt et à la diffusion de documents scientifiques de niveau recherche, publiés ou non, émanant des établissements d'enseignement et de recherche français ou étrangers, des laboratoires publics ou privés. 


\title{
Study on Finding Effective Measures in Education to Counter Googling Action Based on TRIZ
}

\author{
Yutaka Takafuji 1,2 \\ 1 Tokyo City University, Setagaya Tokyo 158-8557, Japan, \\ ytakafuj@tcu.ac.jp \\ 2 13-8, Jingu 3-chome, Nara-shi, Nara, 631-0804, Japan, \\ ytakafuji@me.com
}

\begin{abstract}
One of the recent issues in education at the university is that students tend to search to find directly specific solutions to the problems by Googling. As this behavior prevent students from acquiring expected educational effect, counter measure is necessary. However, this behavior is closely related to large change of environment provided by Information Technology (IT), finding counter measure is not easy. Therefore, a study is made on the above issue exploiting TRIZ. From the results a countermeasure to the above issue is proposed. As relevant conflicting features are unfamiliar to the teaching stuff, finding conflicting features and solutions for above problem with TRIZ is discussed in detail to enlighten teaching stuff, who are unfamiliar to the TRIZ. The problem introduced by Googling is taken as contradiction between "Saving time of busy students, and reducing energy consumption at the brain during thinking", and "Productivity, Adaptability or Versatility, Reliability, Manufacturing precision, and Loss of information" . We found approach of "exchanging the role of teacher and student" which will encourage students to widen and deepen their thought, in addition to the ordinary well-known approaches from the study. Finally, additional study by matrix 2010 proposed by Mann is made and discussed. ...
\end{abstract}

Keywords: conflicting features, education, googling, Matrix 2010, TRIZ

\section{Introduction}

The important goal of university education is not only to develop wide and deep knowledge in the specialized field, but to develop student's creativity and ability of solving unprecedented problems, or acquiring implicit knowledge. Recently, students tend to look directly for the specific solution to the problem by Googling. As this behavior seems strongly related to the changed environment provided by Information Technology (IT), changing their mind is difficult. They are too busy with part-time jobs, in communicating with their friends and class mates, gaming, and watching movies, etc. This behavior prevents them from deep and global thinking, acquiring ability of solving unprecedented problems, 
and to learn something to develop creativity and implicit knowledge. Therefore, establishing effective countermeasure is strongly demanded in the university education. To find effective solutions to the above issue, TRIZ(Russian acronym for "Theory of Inventive Problem Solving" ) [1] was exploited in the present work.

There may be a question, whether TRIZ framework can be applied to educational issues, since TRIZ was developed for technical problems based on the previous inventive ideas in the engineering or science fields. However, one of the basic ideas of TRIZ is that "someone, somewhere has most likely already solved something like present problem" [2] and based on the philosophy, that different disciplines don't communicate each other, and consequently much re-inventing is made. In addition, as strategies of TRIZ is highly abstracted, well-structured, and reduced to be only 40 principles, does help in contradiction elimination successfully. Considering above features, TRIZ seems also applicable to the nontechnical fields.

Recently works on the business and management are reported $[2,3]$, including an example of successful, win-win solutions in a business context [2]. Examples of using TRIZ in the educational field are also found [4,5]. Marsh, et al. [4] has given excellent and helpful work, where 40 principles $[1,6]$ are interpreted to the education related terms. However, as conflicting features are given as technical words unfamiliar to the teaching stuff, finding suitable conflicting features are still difficult for teaching stuff. Therefore, finding effective solutions and showing some examples of finding conflicting features and solutions for above problem with TRIZ seems to be valuable. Detailed process is discussed in the following section. Finally, additional study by using Matrix 2010 proposed by Mann [7], where parameters related to intangible things are added, on above problem is discussed.

\section{Contradiction Matrix and Analysis}

As mentioned above, one of important goal of education at the university is to achieve student's creativity and ability of solving unprecedented problems, and implicit knowledge, which are closely related with the intellectual ability discussed by Sternberg [8]. In his discussion, the investment theory for creativity is proposed. According to his theory, the confluence of six resources listed below, is required.

- Intellectual ability

- Knowledge

- Styles of thinking

- Personality

- Motivation

- Environment

As our problem seems to be closely related with 'Intellectual ability", "Knowledge", "Motivation", and "Environment" from above six resources, we will discuss these four resources. The intellectual ability consists of three skills, the 
synthetic skill, the analytic skill, and the practical-contextual skill. He discussed that synergy of these skills will improve creativity, but lack of any one will hinder creativity. To have correct and meaningful results based on the information by 'googling', intellectual ability above certain threshold is required, as shown in Fig. 1. However, acquiring or improving intellectual ability is not expected

\begin{tabular}{lcc}
\hline Intellectual ability & Required & Acquired \\
\hline Synthetic Skill & Yes & No \\
Analytic Skill & Yes & No \\
Practical Contextual Skill & Yes & Yes (limited) \\
\hline
\end{tabular}

Fig. 1. Required intellectual skills to have meaningful results by 'Googling' and intellectual skills expected to be acquired.

through 'googling' to find directly specific solution, where little intellectual activity is made. Students will develop and acquire their intellectual ability through hard brain activity and go through barriers where very hard brain activity is required. This is why 'googling' is the problem, and countermeasure is necessary. When a class project is given to the students, they tend to look for the specific solution directly in the cyber space (Googling). Reasons of this behavior are as follows: less time due to busy with part-time work, busy on the smartphone, cannot see how to approach due to lack of knowledge or background of the expected level, etc. This is the motivation to try to use TRIZ for solving above issue.

Although there are approaches to develop creativity [8, 9], and to develop creativity is even the most important in education, approaches to creativity is beyond current scope, and we will focus our discussions to the counter googling in the present paper.

To use TRIZ to solve above problem, at first two conflicting features have to be clarified. Then the features closest to the problem is selected out from the Altshuller's matrix $(39 \times 39$ contradiction matrix $)[1,6]$, where feature to be improved is given as the row, and feature that is getting worse is given as the column of the matrix. Several inventive principles are shown as specific numbers assigned to the inventive principles at the crossover of matrix. Then these principles have to be considered and analyzed to choose and focus on several promising candidates. The final step is finding the ideal final solution by analyzing and modifying these candidates until the useful practical solutions are obtained. As TRIZ is highly conceptual and abstracted framework, it is important to consider and analyze these candidates from various point. In this step, at least some experiences and knowledges of the relevant field are important. In the present approach, problem introduced by Googling is taken as contradiction between following features. From the teaching stuff point of view, features to be improved are, "24 Loss of Information", "27 Reliability", "29 Manufacturing Precision", and "35 Adaptability or Versatility". Features getting worse 
are, "22 Loss of Energy", "25 Loss of Time", and "28 Measurement Accuracy". "Loss of Information" is related to losing of various knowledges which is to be acquired, if they take an orthodox way as teachers expect, and expected to be improved. "Reliability" is related to the quality and reliability of acquired intellectual skill expected to be improved. "Manufacturing Precision" is related to the quality and correctness of acquired ability and knowledge, which is the products of education. "Adaptability and versatility" is related to the ability of applying acquired knowledge to solve various problems, including unprecedented problems. Generally, education to improve above knowledge and ability requires much time and hard brain activity. Therefore, these activities are considered to increase time and energy consumption, and let "Loss of Energy", and "Loss of Time" worse. "Measurement Accuracy" is related to the evaluation of acquired ability, which is considered to become more difficult to evaluate with improving ability, especially acquired implicit knowledge.

So far, study on the change of brain glucose metabolism with cognitive activity is mainly focused on understanding Alzheimer's disease using Positron Emission Tomography (PET). Reduction of brain glucose metabolism from normal cognition to Alzheimer's disease [10] is known. Increment in glucose metabolism (directly connected to energy consumption) by intellectual brain activity is reported based on the study on the change of regional cerebral glucose consumption and regional cerebral blood flow [11], though the change is not large compared with basic brain glucose metabolism at rest. Therefore, assumption of increasing energy consumption by cognitive activity at the brain seems reasonable. From the selected conflicting features, candidates to be studied are picked out from the Altshuller's contradiction matrix. Relevant part of the matrix is shown in Fig.2.

\begin{tabular}{lll}
\hline Features to be Improved & Features Getting Worse & Suggested Principles \\
\hline 24 Loss of Information & 22 Loss of Energy & 19,10 \\
& 25 Loss of Time & $24,26,28,32$ \\
& 28 Measurement Accuracy & N/A \\
\hline 27 Reliability & 22 Loss of Energy & $10,11,35$ \\
& 25 Loss of Time & $10.30,4$ \\
& 28 Measurement Accuracy & $32,3,11,23$ \\
\hline 29 Manufacturing Precision & 22 Loss of Energy & $13,32,2$ \\
& 25 Loss of Time & $32,26,28,18$ \\
& 28 Measurement Accuracy & N/A \\
\hline 35 Adaptability or Versatility & 22 Loss of Energy & $18,15,1$ \\
& 25 Loss of Time & 35,28 \\
& 28 Measurement Accuracy & $35,5,1,10$ \\
\hline 39 Productivity & 22 Loss of Energy & $28,10,29,35$ \\
& 25 Loss of Time & N/A \\
& 28 Measurement Accuracy & $1,10,34,28$ \\
\hline
\end{tabular}

Fig. 2. Altshuller's contradiction matrix. Only part of interest is shown. 


\section{Analysis of Principles and Finding Solutions}

From contradiction matrix of Altshuller, we can know candidate principles given at the crossover. From a part of matrix shown in Fig.2, we can find candidate principles to be studied. All the candidate principles given in the matrix crossover of current relevant features are picked up and shown in Fig.3. From Fig.3, we can find several principles related to well known "Active Learning", and of course considered to be very effective and useful. However, we are looking for another more effective solution as countermeasure for "googling" problem.

\begin{tabular}{|c|c|}
\hline Principle & Possible Solution for Educational Case \\
\hline \#1 Segmentation & - Tears process of solving into flow chart to clarify algorithm. \\
\hline \multirow[t]{2}{*}{ \#2 Taking Out } & - Organizing multiple classes based on the experience, ability, etc. for efficient teaching. \\
\hline & - Tear lecture contents shorter and insert discussions and practices. \\
\hline \#3 Local Quality & - Organize remedial class. \\
\hline \#4 Asymmetry & - Assign seating position of non-aggressive student close to teacher. \\
\hline \#5 Merging (Combining) & - Combine lecture with experience, practice, simulation and discussion. \\
\hline \#10 Preliminary Action & - Assignment question for the "Active Learning". \\
\hline \#11 Beforehand Cushioning & - Assignment question for the "Active Learning". \\
\hline \multirow[t]{3}{*}{ \#13 The Other Way Round } & - Make a flip question in the "Active Learning". \\
\hline & (Add new point of view by changing stand point/environment) \\
\hline & - Exchange role of teacher and student. \\
\hline \multirow[t]{2}{*}{ \#15 Dynamics } & - Change curriculum according to the relevant student's level. \\
\hline & (Prepare plurality courses to adjust student's level) \\
\hline \multirow[t]{2}{*}{ \#18 Mechanical Vibration } & - Prepare plurality of class projects and decide next action according to the reaction of students. \\
\hline & - Vibrate conditions under study to change view point for better understanding. \\
\hline \#19 Periodic Action & - Use periodic test and discussion. \\
\hline \multirow[t]{3}{*}{ \#23 Feedback } & - Introduction of PDCA cycle for lecture improvement. \\
\hline & - Make feedback to the results of tests, reports, etc. \\
\hline & - Use questionnaire to check understanding status etc. \\
\hline \multirow[t]{2}{*}{ \#24 Intermediary } & - Require student to include intermediate calculation or thought in the solution. \\
\hline & - Use interim tests to give chances of feedback to students and teacher. \\
\hline \#26 Copying & - Use computer simulation as replaces of physical phenomena. \\
\hline \#28 Mechanics Substitution & - Replace physical phenomena by electrical data (simulation etc.). \\
\hline \#30 Flexible Shells and Thin Films & - Use one-on-one teaching (teaching aides). ${ }^{\dagger}$ \\
\hline \multirow[t]{2}{*}{ \#32 Color Changes } & - Use colored text for emphasis in the slide. \\
\hline & - Make regulation to use colored texts to clarify cited part in the report. \\
\hline \multirow[t]{2}{*}{ \#34 Discarding and Recovering } & - Change instructional activities to maintain student's interes. ${ }^{\dagger}$ \\
\hline & - Cencourage revising and sharing lesson plans. ${ }^{\dagger}$ \\
\hline \#35 Parameter Change & $\begin{array}{l}\text { - Exchange role of teacher and student. } \\
\text { (Parameter: Man, Function: Lecture) }\end{array}$ \\
\hline
\end{tabular}

Fig. 3. Suggested inventive principles on the Altshuller's matrix. Cited ideas from Marsh [5] is indicated by $\uparrow$. 


\subsection{Principles for Countermeasure to Googling}

We have analyzed ideas of these principles for countermeasure to Googling through discussions and studies. The specific numbers for the principles are denoted by the prefixed \#. Large part of the ideas was well-known and discussed among teachers, and thought to be useful. However, we have chosen several principles which are considered to be useful approach to improve especially "Googling" related problems. They are, \#1, \#13, \#26, \#28, \#32, and \#35. Ideas of countermeasure from these principles are explained below.

The first one is to tear process of solving problems into flow chart to clarify algorithm (\#1), which will give students chances to recognize and clarify problem solving approach as algorithm. As this principle comes from contradiction between "adaptability or versatility" and "loss of energy", result seems reasonable. The second is to exchange role of teacher and students (\#13 and \#35), which is considered to drive students to deeper and wider ranged considerations and will help student to acquire higher level ability to solve unprecedented problems, as student has to prepare much more deeper and wider ranged thought and research and materials to teach, and will raise their motivation. In another word student can acquire or improve intellectual ability by these approaches. As these principles come from contradiction between "manufacturing precision" and "loss of time", and between "adaptability or versatility" and "loss of time", results also seem reasonable. The third is to use computer simulation as replaces of physical phenomena (\#26 and \#28). As these principles come from contradiction between "loss of information or manufacturing precision or adaptability or versatility" and "loss of time", and between "productivity" and "loss of energy", suggested principles also seem reasonable. Although experience on the authentic physical phenomena is better than simulation, condition settings may be changed easier and much more things could be learned in much shorter time. Through experiences students can acquire much better understandings, students can see more various phenomena and can compare with theory and their knowledge. And in addition, simulation meets preference of students. If simulation is combined with the lecture on the theory, it will become a very powerful tool for better understanding for students, and will improve their knowledge and motivation. The fourth is to use colored texts to clarify cited part in the report (\# 32). As this principle comes from contradiction between "loss of information or manufacturing precision" and "loss of time", suggested principle again seems reasonable. This force student to include much more original thought and materials, which is impossible by 'Googling' only to find specific solution. This may improve their knowledge and intellectual ability. Thus, three of the six resources of Sternberg [8] seem satisfied.

\subsection{Improving Evaluation Accuracy}

For effective education, evaluation of student's progress is essential. To improve evaluation accuracy of the acquired ability of solving unprecedented problems 
and implicit knowledge, principles \# 1, \# 5, \# 23, and \# 35 are chosen. Ideas of improving evaluation accuracy from these principles are explained below. The first one is to tear process of solving into flow chart to clarify algorithm (\#1). This may help to see the level of student's understandings and knowledge level more correctly. The second is to combine lecture with experience, practice, simulation and discussion (\# 5). By discussing with students, student's understandings and knowledge level could be seen more correctly. The third is to make questionnaire to check understanding status etc. (\# 23). This may also be helpful to check student's understandings and knowledge level correctly. The final one is to exchange role of teacher and student (\# 35). From the contents and way of teaching by students, their understandings and knowledge level could be evaluated more correctly.

\subsection{Application of Simulation to the Oscillatory Phenomena}

From above discussions, computer simulation can replace physical phenomena by electrical data. Although observing authentic physical phenomena is better than simulation, students can observe much more phenomena. Response of the system under various expected conditions could be learned easier and in much shorter time. As a teaching material, oscillatory phenomena, which is seen in various systems in dynamics, RLC circuits, electro-mechanical system, etc., are often taken. However, differential equation, necessary to understand these phenomena, sometimes becomes an obstacle for some students who don't like math. Therefore, following strategy is taken. First let student to have better understanding of phenomena through simulation, and then teach differential equation to understand the relationship between equations and phenomena. This approach will help students to have better understanding. As teaching materials, we have used well-known circuit simulator (Spice, developed at the University of California, and most widely used) to simulate response of RCL circuits and simple harmonic motion of mass point, as both systems are expressed by the same differential equation. Difference is only its constants and dimensions. Therefore, a circuit simulator can be used to simulate both systems. Followings are the examples of simulated response of RCL circuit, and simple harmonic motion of a mass point. Simulated current flow for various cases including critical damping, are shown in Fig.4. Next example is simple harmonic motion of mass point. The results are shown in Fig.5, which is exactly same as the results for RCL circuit, if $m=1[\mathrm{~kg}], \gamma=0 \sim 40[\mathrm{~Pa} \cdot \mathrm{s} / \mathrm{m}], k=100[\mathrm{~N} / \mathrm{m}]$.

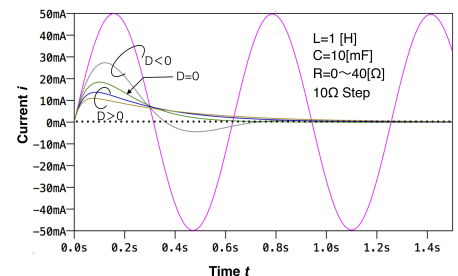

Fig. 4. Current response of RLC series circuit.

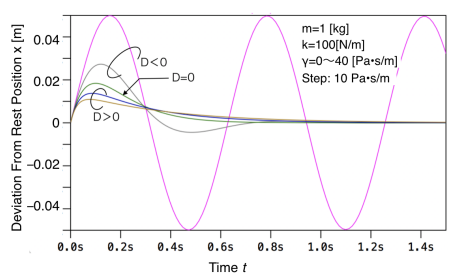

Fig. 5. Mechanical response of horizontal pendulum. 


\section{Additional Features and Principles from Matrix 2010}

In the Matrix 2000 proposed by Mann, conflicting features are increased from 39 of classic TRIZ to 50, and inventive principles are increased from 40 to 82 . Increased features and principles are mainly reflection of recent progress of nanoand bio-technologies. In addition, intangible parameters, which is related to motivation and discourage or idle feelings, are added. Therefore, as added part is considered to be strongly related to "Googling Problem", we have made additional study utilizing Matrix 2010.

\subsection{Contradiction Analysis Using Matrix 2010}

Again, from teacher's point of view, added features to the Matrix 2010 to be improved are, "11 Information Quantity", and "47 Positive Intangible Things". Added features getting worse is, "48 Negative Intangible Things". "Information Quantity" is related to the acquired amount of ability of solving unprecedented problems and amount of the implicit knowledge, and "Positive Intangible Things" is related to motivation, and "Negative Intangible Things" is related to discouraging or lazy feelings. Other features are the same as those of classical Altshuller's matrix, discussed in the previous section, though the assigned numbers are modified.

Relevant part of the matrix is shown in Fig.6. From a part of Matrix 2010 shown in Fig.6, some of the candidate principles currently relevant features are picked up and shown in Fig.7. From Fig.7, we have had several new candidates of countermeasure for "googling problem". A part of assigned specific numbers for the principles are modified in Matrix 2010. Again, the specific numbers for the principles are denoted by the prefixed \#. Large part of the ideas was overlapped with the principles obtained from classical Altshuller's matrix. However, we have found several new principles. They are, \#6, \#7, \#12, \#17, \#25, \#37, and \#40. Ideas of countermeasure from these principles are explained below. The first one is to create purpose of the learning through communicating authentic, real world ex-

\begin{tabular}{lll}
\hline Features to be Improved & Features Getting Worse & Suggested Principles \\
\hline 11 Information Quantity & 26 Loss of Time & $2,7,3,19,28,13,17$ \\
& 27 Loss of Energy & $2,10,3,6,28,13$ \\
& 48 Intangible Negative Things & $7,1,24,13,35,25$ \\
& 50 Measurement Accuracy & $37,3,17,28,24,4,13$ \\
\hline 32 Adaptability or Versatility & 48 Intangible Negative Things & $13,36,40,1,24$ \\
\hline 35 Reliability & 48 Intangible Negative Things & $23,3,37,17,35,28$ \\
\hline 42 Manufacturing Precision & 48 Intangible Negative Things & $2,15,24,5,19$ \\
\hline 44 Productivity & 48 Intangible Negative Things & $23,15,1,19,25$ \\
\hline & 26 Loss of Time & $5,13,10,35,24,40$ \\
& 27 Loss of Energy & $2,25,18,13,12,28$ \\
\hline
\end{tabular}

Fig. 6. Mann's Matrix 2010. Only a part of interest, newly introduced, is shown. 
periences (\# 7), which will give students chances to recognize purpose clearly and improve motivation. The second is to use grouping of students whose grades and activities are similar, to promote discussions (\# 12), which will encourage discussions and will improve motivation of students. The third is to utilize class room under jamming to prevent students from accessing internet (\# 17), which will physically force to stop "Googling". The fourth is to get synergy by mixing motivated students (mentors) with less motivated students (\# 37), which will also improve motivation of less motivated students. From above discussions, we have reached conclusion, " \# 7, \# 12, \# 37" to improve motivation of students, and "\# 17" to physically prohibit "Googling" as the Ideal Final Result (IFR), which corresponds to "Environment" of the six resources [8] . These results are

\begin{tabular}{|c|c|}
\hline Principle & Possible Solution for Educational Case \\
\hline \#1 Segmentation & - Tears process of solving into flow chart to clarify algorithm. \\
\hline \multirow[t]{2}{*}{ \#2 Taking Out } & - Organizing multiple classes based on the experience, ability, etc. for efficient teaching. \\
\hline & - Tear lecture contents shorter and insert discussions and practices. \\
\hline \#3 Local Quality & - Organize remedial class. \\
\hline \#4 Asymmetry & - Assign seating position of non-aggressive student close to teacher. \\
\hline \#5 Merging (Combining) & - Combine lecture with experience, practice, simulation and discussion. \\
\hline \#6 Universality & - Use rubrics, checklists, and other scoring tools to standerdize expectations. ${ }^{\dagger}$ \\
\hline \#7 Nested Doll & - Create purpose for learning through communicating authentic real world experiences. ${ }^{\dagger}$ \\
\hline \#10 Preliminary Action & - Assignment question for the "Active Learning". \\
\hline \#12 Equipotentiality & - Use grouping of students whose grades and activities are similar, to promote discussions. \\
\hline \multirow[t]{3}{*}{ \#13 The Other Way Round } & - Make a flip question in the "Active Learning". \\
\hline & (Add new point of view by changing stand point/environment) \\
\hline & - Exchange role of teacher and student. \\
\hline \multirow[t]{2}{*}{ \#15 Dynamics } & - Change curriculum according to the relevant student's level. \\
\hline & (Prepare plurality courses to adjust student's level) \\
\hline \#17 Another Dimension & - Prepare and use class room under jamming to prevent students from using web access. \\
\hline \multirow[t]{2}{*}{ \#18 Mechanical Vibration } & - Prepare plurality of class projects and decide next action according to the reaction of students. \\
\hline & - Vibrate conditions under study to change view point for better understanding. \\
\hline \#19 Periodic Action & - Use periodic test and discussion. \\
\hline \multirow[t]{3}{*}{ \#23 Feedback } & - Introduction of PDCA cycle for lecture improvement. \\
\hline & - Make feedback to the results of tests, reports, etc. \\
\hline & - Use questionnaire to check understanding status etc. \\
\hline \multirow[t]{2}{*}{ \#24 Intermediary } & - Require student to include intermediate calculation or thought in the solution. \\
\hline & - Use interim tests to give chances of feedback to students and teacher. \\
\hline \#25 Self Service & - Utilize rubrics quantifiable scoring systems. ${ }^{\dagger}$ \\
\hline \#28 Mechanics Substitution & - Replace physical phenomena by electrical data (simulation etc.). \\
\hline \multirow[t]{2}{*}{ \#35 Parameter Change } & - Exchange role of teacher and student. \\
\hline & (Parameter: Man, Function: Lecture) \\
\hline \#37 Thermal Expansion & - Get synergy by mixing motivated students (mentors) with less motivated students. ${ }^{\dagger}$ \\
\hline \multirow[t]{2}{*}{ \#40 Composite Materials } & - Use composite teaching materials of visual, simulation, presentation, lecture, discussion, etc. \\
\hline & - Introduce training/teaching with a combination of lecture, simulations, on-line learning, etc. ${ }^{\dagger}$ \\
\hline
\end{tabular}

Fig. 7. Suggested inventive principles on the Mann's Matrix 2010. Cited ideas from Marsh [5] is indicated by $\dagger$ 
and "\# 17" to physically prohibit "Googling" as the Ideal Final Result (IFR), which corresponds to "Environment" of the six resources [8]. These results are mostly related with the emotional response of students, as expected, and two of the six resources of Sternberg [8] are realized,

\section{Conclusion}

From above discussions, exchanging role of teacher and students, and using simulation to help better understanding of phenomena were chosen as IFR for both countermeasure to "Googling Problem" and "Correct evaluation". And exchanging role of teacher and students was again chosen as IFR for "Correct evaluation". From these countermeasures, three (intellectual ability, knowledge, motivation) and as a countermeasure of environment four resources of the six resources of Sternberg will be satisfied. Remaining two are 'the styles of thinking' and 'the personality', and further works for these resources are necessary. Additional IFR is obtained by using Matrix 2010 of Mann, which is mainly related with emotional response of man. A complete solution of physically rejecting "Googling" is obtained also by using Matrix 2010. However, this principle comes from the feature related with emotion, relationship between them is unclear, and still further work and discussions are necessary.

\section{Acknowledgements}

The author gratefully acknowledges Dr. S. Ukon of Tokyo City University, and Dr. H. Yamazaki of Fukuoka Institute of Technology for useful discussions.

\section{References}

1. Altshuller, G. S.: Creativity as an Exact Science, Translated by Anthony Williams. Gordon \& Breach, NY (1988).

2. Mann, D.L.: The TRIZ Journal, May (2002).

3. Ruchti, B., Livotov, P.: The TRIZ Journal, December (2001).

4. Marsh, D. G., Waters, F. H., Marsh, T. D.: The TRIZ Journal, April, (2004).

5. Marsh, D. G., Waters, F. H., Mann, D.L.: The TRIZ Journal, November (2002).

6. Takagi, Y.: Inventive Principles of TRIZ(In Japanese). 1st edn. Discover 21, Tokyo (2014).

7. Mann, D., : Matrix 2010: Re-updating the TRIZ Contradiction Matrix, IFR Press, UK (2009). [Japanese tranlation: by Nakagawa,T.: CrePS Institute, Chiba, Japan (2014)]

8. Sternberg, R. J.: Creative Research Journal, 18, 87-98 (2006)

9. Edmondson, A. C., Harvey, J-F, : Human Resource Management, 28, 347-360 (2018)

10. Mosconi, L.,Mistur, R., Switalski, R, Tsui, W. H., Glodzik, L., Li. Y., Pirraglia, E., Santi, S. D., Reisberg, B., Wisniewski, T., de Leon, M. J.: Eur J Nucl Med Mol Imaging, 35, 811-822 (2009).

11. Roland, P. E., Eriksson, L., Stone-Elander, S., Widen, L.: The Journal of Neuroscience, 7, 2373-2389 (1987). 